\title{
Concepções de sujeito e autonomia na humanização em saúde: uma revisão bibliográfica das experiências na assistência hospitalar
}

\author{
Concepts of subject and autonomy in humanization of \\ healthcare: a literature review of experiences in hospital
} service

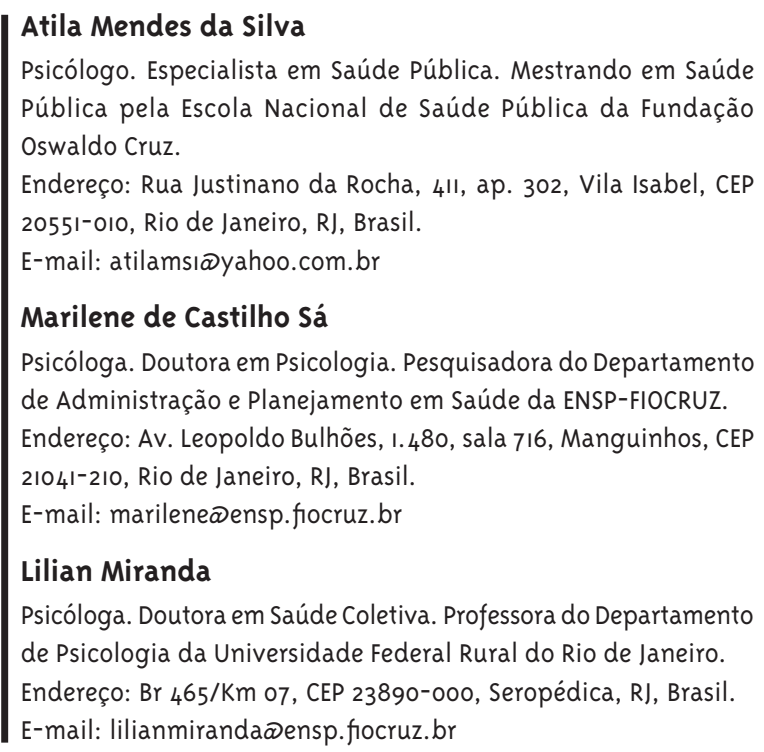

\section{Resumo}

Este trabalho buscou analisar as concepções de sujeito e autonomia presentes em artigos científicos sobre experiências de humanização desenvolvidas em hospitais brasileiros, publicados entre 2004 e 2010. Realizou-se um levantamento bibliográfico na base de dados da Biblioteca Virtual de Saúde, a partir dos descritores "humanização da assistência hospitalar" e "humanização da atenção hospitalar", elegendo-se para análise artigos que apresentavam propostas de intervenção ou avaliação da assistência hospitalar, com foco na humanização. Percebeu-se que grande parte dos artigos enfatiza que as iniciativas de humanização devem proporcionar uma compreensão mais ampliada dos usuários, sensível a aspectos que os autores avaliam como negligenciadas nos serviços de saúde, tais como o reconhecimento da singularidade, complexidade e individualidade. Já os trabalhadores são entendidos como portadores de certo voluntarismo pessoal e como sujeitos que devem ativar suas habilidades para a humanização do cuidado em saúde. Entretanto, a análise desses artigos permite apontar a escassez de discussões acerca das dimensões intersubjetivas, organizacionais, político-institucionais e sociais que envolvem os projetos de humanização. Os sujeitos - profissionais e usuários, são entendidos, predominantemente, a partir de concepções que ressaltam o individualismo e desconsideram a rede de dependências inerente às relações humanas, os jogos de poder e os afetos (amistosos e hostis) que as 
alimentam. Aponta-se, por fim, um distanciamento das concepções de sujeito e autonomia presentes nos artigos analisados com relação às proposições presentes na Política Nacional de Humanização e na produção teórica do campo do planejamento e gestão em saúde.

Palavras-chave: Sujeito; Autonomia; Humanização da assistência; Humanização da assistência hospitalar; Política Nacional de Humanização.

\section{Abstract}

This paper investigates the concepts of subject and autonomy in scientific articles about humanization experiences developed in Brazilian hospitals, published between 2004 and 2010. We performed a literature review on the Virtual Library on Health database, using "humanization of hospital assistance" and "humanization of hospital care" descriptors; we chose to review articles that presented proposals for intervention or assessment of hospital care with a focus on humanization. It was noticed that most articles emphasized that initiatives of humanization should provide users with a more expanded understanding, sensitive to issues that the authors consider neglected at health services, such as the recognition of the patient's uniqueness, complexity and individuality. In contrast, healthcare workers are seen as showing a certain amount of voluntarism and as subjects that should enable their skills towards the humanization of healthcare. However, analysis of these items allows us to point out the lack of discussion about the inter-subjective, organizational, political, institutional and social dimensions that involve the projects of humanization. Subjects - professionals and patients, are seen predominantly from conceptions that emphasize individualism and bypass the network of dependencies inherent to human relationships, the power plays and affections (friendly and hostile) that feed them. At last, it is pointed out the gap between the concepts of subject and autonomy in the articles analyzed with respect to the propositions present in the National Humanization Policy and in healthcare management and planning theoretical field.

Keywords: Subject; Autonomy; Humanization of Health Care; Humanization of Hospital Care; National Policy of Humanization. 


\section{Introdução}

Nos últimos anos, temas como integralidade da assistência, interdisciplinaridade e humanização vêm ganhando cada vez mais atenção nas discussões sobre saúde. Isso reflete no aumento de práticas que pretendem pautar-se nessas propostas e no número de produções teóricas que tratam desses temas, a partir de diferentes entendimentos.

Nesse contexto, as iniciativas de humanização de assistência passam a ganhar mais expressão, entrando inclusive na pauta da $11^{\text {a }}$ Conferência Nacional de Saúde, ocorrida no ano de 200o, a qual teve como tema: "Efetivando o SUS: Acesso, Qualidade e Humanização na Atenção à Saúde com Controle Social”. A partir de então, começam a surgir uma série de experiências de humanização da assistência, sendo seguidas de iniciativas no campo político-normativo. Como exemplo de tais iniciativas, podemos citar o surgimento do Programa Nacional de Humanização da Assistência Hospitalar (PNHAH) em 2001, sendo substituído em 2003 pela Política Nacional de Humanização (PNH). A PNH traz como proposta, dentre outras coisas, a produção de autonomia e protagonismo dos diferentes sujeitos implicados no processo saúde-doença, bem como a valorização da dimensão subjetiva e social nas práticas de atenção e gestão da saúde (Brasil, 2010).

Em um artigo que analisa a produção bibliográfica oficial a respeito da humanização, Deslandes (2004) afirma que o termo humanização vinha sendo empregado constantemente de forma a servir como emblema para uma gama de práticas nem sempre ligadas entre si. Para a autora, este termo serve de apoio a um amplo conjunto de iniciativas, mas não possui uma definição muito clara. Comumente designa a forma de assistência que valoriza a qualidade do cuidado do ponto de vista técnico, associada ao reconhecimento dos direitos do paciente, de sua subjetividade e cultura, além do reconhecimento do profissional. Nessa direção, Benevides e Passos (2005) afirmam ainda que, em algumas práticas, os sentidos de humanização aparecem ligados às ideias de voluntarismo, assistencialismo, paternalismo, ou mesmo de um tecnicismo, vinculando-se ao modo de gestão do racionalismo administrativo e da qualidade total.

De maneira semelhante às experiências de humanização, as discussões a respeito da noção de sujeito e subjetividade, conforme apontam alguns autores (Onocko Campos, 2005; Ferreira-neto e col., 2011), são relativamente recentes no campo da Saúde Coletiva e vêm ganhando expressão nos últimos anos. A nosso ver, tais discussões são o sustentáculo das propostas e da própria política de humanização.

Entendendo que um conceito surge como resposta a problemas da realidade, consideramos que o modo como ele é concebido reflete o que caracterizaria tais problemas e as estratégias de intervenção sobre eles. Assim, supõe-se que a forma como a noção de sujeito é concebida, bem como o modo como se aborda a temática da autonomia dos trabalhadores e usuários nos serviços de saúde podem contribuir para a compreensão daquilo que se pretende transformar no campo assistencial, dos desafios que se apresentam a essa transformação e daquilo que se compreende como "meta" a ser alcançada pelas iniciativas de humanização.

Sendo assim, a análise das concepções de sujeito e autonomia abre brechas para que possamos inferir quais são os possíveis caminhos e estratégias que vêm sendo realizadas ou ambicionadas pelas experiências de humanização nos serviços de saúde, uma vez que tais estratégias devem ser consideradas como indissociáveis dos modos de compreender o sujeito e a autonomia.

Desta forma, o presente artigo apresenta os resultados de uma pesquisa bibliográfica, realizada durante o curso de especialização em Saúde Pública na Escola Nacional de Saúde Pública, que buscou analisar as concepções de sujeito e autonomia presentes em um universo de artigos que tratavam de experiências de humanização da assistência hospitalar. Embora se reconheça a complexidade e a especificidade da realidade hospitalar, o foco do presente trabalho são as concepções de sujeito e autonomia em experiências de humanização, não cabendo no espaço deste artigo uma discussão sobre a realidade hospitalar. 


\section{Estratégias metodológicas}

A pesquisa descrita neste artigo foi realizada a partir de uma busca de artigos científicos na base de dados da Biblioteca Virtual de Saúde (BVS), em que foram considerados artigos publicados a partir de 2004 (já que a PNH foi implantada em 2003) até abril de 2010, capturados pelos descritores: "humanização da atenção hospitalar" e "humanização da assistência hospitalar".

Foram selecionados 41 artigos científicos para a leitura, através de uma pré-seleção que buscou, a partir da leitura dos resumos dos artigos, identificar aqueles que, pelo resumo, pareciam relatar ou analisar experiências ou iniciativas concretas de humanização em hospitais, não se restringindo a discussões teóricas sobre o tema.

Após a leitura dos 41 artigos, foram selecionados 25 que de fato atendiam aos critérios estabelecidos: relatavam experiências concretas de humanização da assistência hospitalar ou avaliavam a qualidade do cuidado produzido em um determinado hospital, quanto à humanização da assistência. Partiu-se do entendimento de que ao intervir sobre o modo como ocorre a assistência, propondo humanizá-la, ou ainda, ao avaliar a assistência em saúde (tendo enquanto critério de qualidade a humanização da saúde), os autores partem de alguma concepção de humano ou sujeito em sua argumentação.

Uma vez identificados tais artigos, procedeu-se à sua leitura exaustiva, de modo a apreender as concepções de sujeito e autonomia que expressam. A partir do material dos próprios artigos, delineamos algumas categorias que procuram expressar as concepções identificadas e as organizamos em dois grandes grupos, conforme explicitamos mais adiante.

Em seguida, foi realizada a análise deste material através do diálogo com autores da Saúde Coletiva, especialmente, tomando como base para a análise, a necessidade de reconhecimento da intersubjetividade e do atravessamento dos afetos amorosos e destrutivos nos cuidados em saúde, temática abordada de diferentes modos por autores da Saúde Coletiva (Campos, 2010; Cecílio, 2007; Deslandes, 2004; Merhy, 1998; Onocko Campos, 2005; Sá, 2009). Complementarmente, o material foi analisado à luz de algumas discussões trazidas pela psicanálise e pela psicossociologia francesa que consideramos importantes para a compreensão dos limites às experiências de humanização, como a problemática da dinâmica da sociedade contemporânea, fortemente marcada pela violência para com expressões de alteridade e pelo declínio da função dos coletivos na mediação e organização das formas de sociabilidade (Birman, 2006, 2010), ou da lógica neoliberal, indutora do individualismo (Enriquez, 2001).

Vale ressaltar que se considerou a menção que os artigos faziam a outros termos além de "sujeito", tais como: humano, indivíduo, cliente, etc. Isso se deu porque o objetivo não era a mera verificação da presença dos termos "sujeito" e "autonomia", mas sim a compreensão do modo como essas noções são entendidas e abordadas nos artigos, ainda que apresentados através de outros termos.

\section{Resultados e discussão}

Objetivando identificar e analisar as concepções de sujeito que subjazem às experiências descritas nos artigos, foram definidos dois grandes grupos: 1 . Concepções de sujeito voltadas para os usuários dos serviços de saúde; 2. Concepções de sujeito voltadas para o profissional de saúde (normalmente vinculados à relação profissional de saúde - usuários). Cabe observar que as concepções de sujeito e autonomia analisadas, uma vez apreendidas a partir dos artigos, refletem ou expressam as visões dos autores desses trabalhos que, em alguns casos, são os mesmos atores responsáveis pela implementação das experiências. Mostra-se, ainda, importante afirmar que esses dois grandes agrupamentos de categorias se atravessam, na medida em que, ao se referirem aos profissionais de saúde, os autores indicavam os sentidos atribuídos aos usuários e vice-versa.

\section{Concepções de sujeito e autonomia voltadas aos usuários dos serviços de saúde}

Os artigos analisados expressam uma preocupação em ampliar o modo como os usuários dos serviços de saúde são vistos. Tal ampliação parece se dar a partir da valorização de dimensões relativas aos usuários que os autores dos artigos avaliam como esquecidas ou negligenciadas nos serviços de saúde, tais como 
o reconhecimento da singularidade, complexidade e individualidade dos usuários (Costa e Borenstein, 2004; Seibert e col., 2008; Gomes e col., 2008; Coelho e Rodrigues, 2009), reconhecimento de sua totalidade e integralidade (Santos, 2007; Barbosa e Silva, 2007), reconhecimento de sua legitimidade em realizar escolhas a respeito de seu próprio tratamento (Gomes e col., 2008; Dias e Domingues, 2005; Puplaksis e Ramos, 2006), e o reconhecimento de sua liberdade, enquanto consumidor, de escolher os serviços de saúde que melhor se adequassem a suas demandas (Backes e col., 2007). A valorização desses elementos no processo de interação com o usuário, conforme apontam os artigos, seria um dos principais objetivos a serem alcançados para se chegar à humanização do cuidado. 0 que pode ser exemplificado nos trechos abaixo:

A humanização não deve ser entendida como um discurso, e sim como um ato, o ato de humanizar. Humanizar é fazer boas ações, demonstrar ternura e respeito, sentir o outro; é ver o outro como um ser humano, um ser total: corpo, mente, emoção e espírito (Martins e col., 2008, p. 32, grifo nosso). Pelo exposto, sugere-se que esta mulher, mãe de um recém-nascido de risco, seja assistida pelos profissionais de enfermagem munidos de elementos que viabilizam a prática de um cuidado singular, centrado nas crenças, valores e estilos de vida de cada mulher e sua família (Isehard e col., 2009, p. 121, grifo nosso).

A comunicação adequada do diagnóstico de uma deficiência torna-se atual por meio da discussão sobre a humanização no âmbito da saúde. Quando o profissional olha seu paciente globalmente, ele atua de forma humanizada, preocupando-se com o impacto das informações na família e no paciente (Bazon e col., 2004, p. 97, grifo nosso).

Em contrapartida, nos artigos analisados, a ideia de autonomia dos usuários aparece de maneira tímida, relacionando-se principalmente com a necessidade do aumento da informação destes sobre o seu tratamento, com a defesa de sua participação sobre as decisões a respeito do processo de cuidado e com a sua capacitação para ação autônoma.

Ao abordar o usuário, alguns artigos levam em consideração a autonomia daqueles entendendo- -a principalmente enquanto direito de escolha e participação sobre o processo terapêutico. Esses artigos se pautam no entendimento do sujeito como um cidadão, que, dada essa condição, é dotado de direitos que precisam ser respeitados.

Por um lado, tal concepção se expressa no reconhecimento da necessidade de encaminhamentos que contemplem tais direitos, conforme o trecho abaixo:

Outros aspectos se referem à autonomia da mulher durante todo o processo, com elaboração de um plano de parto que seja respeitado pelos profissionais que a assistirem; de ter um acompanhante de sua escolha; de serem informadas sobre todos os procedimentos a que serão submetidas; e de ter os seus direitos de cidadania respeitados (Dias e Domingues, 2005, p. 700, grifo nosso).

Por outro lado, se expressa na crítica aos momentos em que tais direitos são desrespeitados e a dimensão singular do paciente é obscurecida em favor do cumprimento de rotinas estabelecidas sem a consideração das necessidades subjetivas daquele que a elas é submetido, como no trecho a seguir:

Normas e rotinas de troca de curativos, troca de scalp, entrega da medicação e alimentação foram cumpridas parcialmente. Exigia-se o banho em horários indesejados pelo paciente e era proibido o uso de vestimentas próprias. Constatamos, pois, a despersonalização e imposição de normas, com desrespeito à autonomia e à decisão do paciente. Ignorando a expressão singular dos sujeitos e sua cultura, a organização hospitalar impõe uma rotina que atende, em massa, os pacientes (Gomes e col., 2008, p. 639, grifo nosso).

$\mathrm{O}$ entendimento de autonomia como um direito se expressa, ainda, através da defesa da construção de uma capacidade de ação autônoma nos usuários:

0 respeito pela autonomia implica tratar as pessoas de forma a capacitá-las a agir autonomicamente, enquanto que o desrespeito "envolve atitudes e ações que ignoram, insultam ou degradam a autonomia dos outros e, portanto, negam a igualdade mínima entre as pessoas" (7). (Barbosa e Silva, 2007, p. 547, grifo nosso e grifo do autor).

Dois dos artigos analisados trazem uma crítica ao paternalismo, em sua ação de infantilização 
dos usuários dos serviços de saúde. Para Barbosa e Silva (2007):

... a fragilização do ser humano na posição de "paciente" desfavorece o exercício da autonomia quando ocorre a visão paternalista de que a equipe de saúde detém o poder e o conhecimento, subestimando assim a capacidade do doente em fazer julgamentos com relação a si e a sua saúde (p. 547).

Puplaksis e Ramos (2006) argumentam que o paternalismo no Brasil é facilitado (no que diz respeito à população pobre) devido à baixa escolaridade das pessoas que utilizam os serviços de saúde e que "não têm plena consciência de seus direitos" (p. 321). Dessa forma, para os autores, essa população tem sua autonomia diminuída, devido à falta de possibilidades de escolhas.

Os artigos analisados parecem, em alguns momentos, defender os direitos dos usuários a partir de uma racionalidade instrumental em que se pressupõe a existência de apenas dois polos possíveis: o de dominador e o de dominado (Costa, 2001). Assim, em alguns trabalhos, o paciente é descrito como vítima de imposição de normas e rotinas que desrespeitam sua singularidade, enquanto que em outros, ele é considerado como aquele que merece ser esclarecido de seus direitos, para reivindicá-los perante os profissionais. 0 poder de domínio destes só seria barrado através do exercício de tais direitos.

Mesmo reconhecendo a importância da conscientização para aumentar os graus de autonomia dos usuários nos serviços de saúde, pensamos que é necessário fazer algumas ponderações acerca dessa visão, pois supomos que apenas ter um nível maior de educação, que possibilite aos usuários saberem dos seus direitos, não é suficiente para mudar a dinâmica do encontro profissional de saúde-usuário, intensificando a participação deste último no seu processo terapêutico. Esse problema envolve não só conscientização dos usuários e profissionais, mas também outros fatores presentes na relação intersubjetiva entre esses sujeitos, a qual é atravessada por uma dinâmica imaginária e simbólica, que diz respeito à cultura, mas também aos processos de produção do cuidado em saúde (Sá, 2009; Azevedo e col., 2002).

Nesse sentido, entendemos que o encontro trabalhador de saúde-usuário é constituído por uma relação na qual se desenvolve um jogo de expectativas e produções, já que pressupõe a intervenção de um sujeito sobre outro de tal modo que enquanto um busca a solução de seu problema de saúde, o outro procura dar algum encaminhamento a essa demanda através de um "trabalho vivo em ato" (Merhy, 1998). É interessante notar que, embora os autores dos artigos analisados se refiram a aspectos como singularidade, emoção e crenças, não há uma discussão mais aprofundada a respeito do encontro profissional de saúde-usuário.

Além disso, a argumentação dos artigos analisados, em alguns momentos, parece desconsiderar o saber que o usuário já traz consigo, entendendo-o como alguém que desconhece suas próprias necessidades e, portanto, precisa ser capacitado para adquirir conhecimentos que o possibilitariam exercer o seu direito de cidadania.

Nesse ponto, é interessante retomar a discussão de Onocko Campos e Campos (2006) acerca da coconstrução da autonomia. Para eles, o indivíduo em seu processo de constituição subjetiva somente torna-se um sujeito autônomo a partir da relação que estabelece com o outro. Assim, os autores desvinculam o conceito de autonomia da ideia de independência absoluta.

Dessa maneira, os graus de autonomia do sujeito dependem do modo de funcionamento das organizações de saúde e dos valores que lá são veiculados, mas também da cultura em que o sujeito está inserido (Onocko Campos e Campos, 2006). Assim, concordamos que, no encontro trabalhador de saúde-usuário, para além da oferta de informação e conhecimentos que possibilitariam acréscimos de poder aos usuários, deve-se buscar a coconstrução da autonomia - entendida enquanto o aumento da capacidade de o usuário lidar com sua rede de dependências.

Embora não caiba nos limites deste trabalho discutir as especificidades da realidade hospitalar, vale ressaltar que estas não foram destacadas nos artigos lidos, tampouco relacionadas com os desafios da humanização. De todo modo, é importante ponderar que o tipo de cuidado desenvolvido nesse contexto (que envolve, entre outros aspectos, complexas exigências para a segurança do paciente) requer um grau de protocolização e normatização de certas 
rotinas. Estas, inevitavelmente, se colocam entre o profissional e o paciente, influenciando fortemente o tipo de relação que pode se estabelecer e, podem representar, dependendo da rigidez com que sejam tomadas, a diminuição do tempo livre para a escuta e para a interação.

\section{Concepções de autonomia voltadas aos profissio- nais de saúde}

Foi possível identificar uma tendência nos relatos presentes nos artigos analisados em conceber o profissional de saúde enquanto alguém que deve desenvolver, ou ser previamente dotado de capacidades/habilidades para responder adequadamente às necessidades dos usuários, os quais deveriam ser vistos de maneira mais ampliada pelas práticas de cuidado e assistência hospitalar.

Estas capacidades, por um lado, são entendidas, em alguns artigos, como inerentes aos trabalhadores precisando ser valorizadas/reconhecidas. Nesse sentido, alguns autores também condicionam a humanização do cuidado à "vontade de cada um" em realizar um cuidado de melhor qualidade (Martins e col., 2008; Motta, 2005).

Por outro lado, as capacidades são, também, concebidas enquanto habilidades a serem aprendidas através de conhecimentos científicos ou enquanto habilidades emocionais que poderiam ser construídas.

Dessa forma, abaixo agrupamos em algumas categorias os diferentes modos de conceber os profissionais de saúde, sugeridos pelos artigos analisados. Estas se caracterizam pelo reconhecimento das seguintes capacidades: habilidade de comunicação dos trabalhadores; habilidades emocionais a serem desenvolvidas ou reconhecidas; a capacidade inerente de realizar bons atos; e o desenvolvimento de um espírito empreendedor e proativo nos profissionais de saúde, tendo a humanização como um diferencial competitivo.

\section{Reconhecimento da comunicabilidade/capacida- de de comunicação dos sujeitos}

Alguns dos artigos expressam o entendimento da capacidade de comunicação enquanto algo inerente aos humanos, que deve ser reconhecido (Martins e col., 2008; Prochet e Silva, 2008). Outros, embora não compreendam tal capacidade como própria ao existir humano, valorizam o desenvolvimento de uma capacidade de comunicação nos profissionais de saúde (Motta, 2005; Mendes e col., 2008; Bazon e col., 2004). Esta capacidade, quando aprimorada pelo profissional, tornaria possível a efetivação de um cuidado humanizado, pois contribuiria para a qualificação do encontro profissional de saúde-usuário. O desenvolvimento de tal capacidade é ressaltado como necessário, especialmente no que diz respeito à comunicação de diagnósticos graves. Abaixo, apresentamos trechos de alguns artigos que exemplificam essas questões:

[...] Assim, podemos inferir que, se o profissional possui habilidade de comunicação, terá a capacidade de estabelecer uma relação interpessoal positiva ao interagir com a clientela (Motta, 2005, p. 3).

A comunicação adequada do diagnóstico de uma deficiência torna-se atual por meio da discussão sobre a humanização no âmbito da saúde. Quando o profissional olha seu paciente globalmente, ele atua de forma humanizada, preocupando-se com o impacto das informações na família e no paciente (Bazon e col., 2004, p. 97, grifo nosso).

Um dos artigos (Martins e col., 2008) cita o Programa Nacional de Humanização da Assistência Hospitalar (PNHAH), para afirmar o diálogo como aquilo que caracteriza a especificidade do humano. No entendimento dos autores, este programa concebe que "as coisas do mundo só se tornam humanas quando passam pelo diálogo com o semelhante" (Brasil apud Martins e col., 2008, p. 36).

Como se sabe, esse programa propunha o aumento da capacidade comunicativa como modo de construção de uma nova cultura de atendimento, gerando assim uma assistência humanizada (Deslandes, 2004). Portanto, é possível que a valorização da comunicação sugerida pelos artigos seja, em alguma medida, resultado da influência do PNHAH, que colocava em discussão justamente o reconhecimento da capacidade comunicativa em sua proposta de humanização da assistência em saúde.

Deslandes (2004) faz uma reflexão importante a respeito das ideias que esse programa defende, afirmando que essas propostas de ampliação da comunicação parecerão ingênuas se não houver um reconhecimento da autonomia e legitimidade simbólica dos usuários, cujas manifestações não são, 
a princípio, delegáveis a "tradutores-intérpretes".

Concordamos com a opinião da autora a respeito do reconhecimento da legitimidade dos usuários do serviço de saúde e de sua autonomia enquanto sujeitos no processo saúde-doença. Além disso, observamos que a PNH parece ter avançado nessa discussão ao afirmar a importância do reconhecimento dos atores implicados no processo de produção da saúde. Mas, ainda assim, podemos perceber que os artigos trabalhados mantêm, predominantemente, suas ideias voltadas apenas para a transformação do modo como ocorre o atendimento nos serviços de saúde, baseando suas propostas, dentre outras coisas, em uma ampliação/qualificação da comunicação interpessoal, desconsiderando os afetos de profissionais e pacientes que estão envolvidos nessa comunicação.

2. Sujeito dotado de uma capacidade inerente de realizar bons atos (ter boa vontade/ser benevolente)

Essa categoria emergiu a partir da recorrente apresentação do sujeito trabalhador enquanto um ser dotado de uma inclinação natural para a realização de "bons atos" (Amestoy e col., 2006; Bazon e col., 2004). Como demonstram os trechos abaixo, entende-se que a saúde precisa ser humanizada e, para isso, é preciso que se ativem nos trabalhadores as características de bondade e altruísmo inerentes ao seu ser.

A humanização não deve ser entendida como um discurso, e sim como um ato, o ato de humanizar. Humanizar é fazer boas ações, demonstrar ternura e respeito, sentir o outro; é ver o outro como um ser humano, um ser total: corpo, mente, emoção e espírito (Martins e col., 2008, p. 32, grifo nosso).

Na área da saúde não é possível falar em cuidado sem enfatizar a humanização, isto é, tornar humano, benévolo, sendo entendida como uma medida que busca resgatar o respeito à vida humana em ocasiões sociais, éticas e psíquicas, presente no relacionamento humano, aceitando-se a necessidade de resgatar os aspectos subjetivos, fisiológicos e biológicos.

[...]

É ter capacidade de ser frágil, de chorar, de ser vulnerável, porém, ter vigor, lutar, resistir, compreender e observar a complexa relação entre corpo, mente e espírito (Beccaria e col., 2008, p. 66, grifo nosso).

Segundo Sá (2009), o entendimento do humano enquanto um ser voltado automaticamente para a realização de bons atos tem importantes consequências sobre as práticas de intervenção sobre o cuidado, nomeadas enquanto práticas de humanização. Para a autora, intervenções de humanização da assistência pautadas nesse modo de entender o humano se afinam com estratégias de "sensibilização" e práticas de cunho pedagógico, partindo do pressuposto de que é possível desencadear uma ativação da bondade que os sujeitos trazem consigo ou moldar suas ações para que a disposição à realização de bons atos, que caracterizaria sua essência, torne-se prevalente.

Além disso, Sá (2009) discute o desconhecimento gerado pela utilização do termo humanização para designar a transformação da assistência em prol de um cuidado mais solidário e produtor de autonomia. Para a autora, o termo não coloca em questão a ambiguidade constituinte do sujeito, reafirmando, assim, uma concepção de humano como um ser essencialmente bom. Dessa forma, a utilização desse termo abriria brechas para se pensar que, já que o homem é essencialmente bom, basta sensibilizá-lo para que aja de maneira mais solidária.

Considera-se ainda que algumas propostas ancoradas nesse modo de conceber o sujeito podem se pautar numa visão que compreende o profissional dos serviços de saúde enquanto alguém que se encontra automaticamente comprometido com os ideais de transformação do cuidado, um "trabalhador moral" (Cecílio, 2007). Tal postura desconsidera as possibilidades de divergência ou resistência próprias aos profissionais, que podem estar engajados com diferentes questões sociais (interesses coorporativos, por exemplo) ou subjetivas que levam a divergências com o que é proposto.

Talvez, por não considerarem a condição de cisão e ambivalência do sujeito humano, as propostas presentes nesses artigos busquem identificar no trabalhador uma bondade totalizante, próxima da onipotência, já que associam o humano diretamente à benevolência, altruísmo e à realização de boas ações.

Tais características imputadas ao trabalhador podem se configurar, a nosso ver, numa possível fonte de sofrimento. Ao se desconsiderar caracte- 
rísticas importantes do sujeito como raiva, rancor e medo, incorre-se no risco de exigir do trabalhador um condicionamento automático e alienado de sua ação junto à população usuária. Tal tipo de exigência se faz em detrimento de uma compreensão mais realista da relação entre profissionais de saúde e usuários, compreensão esta que possibilitaria produzir encaminhamentos para as possíveis dificuldades emergentes numa relação que se faz entre sujeitos e que é atravessada, também, por questões sociais, políticas e organizacionais e de diferentes dimensões afetivas.

\section{Reconhecimento da sensibilidade/afetividade dos sujeitos, desenvolvimento de habilidade emocional}

Alguns autores apontam o reconhecimento da sensibilidade e afetividade dos profissionais de saúde como um modo de "humanizar" o cuidado em saúde (Collet e Rocha, 2004; Mendes e col., 2008; Barbosa e Silva, 2007).

A sensibilidade é vista como um meio pelo qual se pode perceber os múltiplos determinantes que envolvem o cuidado dos usuários. Nesse sentido, defende-se a construção de uma relação de empatia entre o profissional de saúde e o usuário enquanto algo que pode minimizar o sofrimento deste. $\mathrm{O}$ desenvolvimento desta capacidade de empatia ou sensibilidade é vista, em alguns momentos, como algo que se constrói a partir de conhecimentos teóricos e/ou habilidades emocionais que serviriam para instrumentalizar os profissionais no encontro com os usuários, de forma a qualificar o cuidado prestado.

Entende-se, portanto, que ações simples como o toque, a conversa, a informação técnica referente ao setor, a informação biológica referente ao cliente e a empatia dos profissionais possam contribuir significativamente para amenizar os efeitos nocivos da internação em UTI, evidenciando, assim, os aspectos positivos para os clientes e seus familiares, facilitando, desse modo, o processo de internação (Silva e Contrin, 2007, p. 150).

Assim, vislumbramos a humanização do trabalho a partir da capacitação da habilidade emocional do profissional para o enfrentamento da dimensão da subjetividade, de modo a criar alternativas para superação das frustrações presentes no ambiente de trabalho (Amestoy e col., 20o6, p. 447).
Com a inclusão da família no processo assistencial nas UTINs [Unidade de Terapia Intensiva Neonatal], emerge a necessidade de instrumentalizar os profissionais com conhecimentos em psicologia familiar, apego entre mãe e filho, relacionamento interpessoal e direitos humanos, para que a atuação seja pautada no modelo de atenção à saúde humanizada (Oliveira e col., 2006, p. 106, 107).

Diferentemente do que propõem os autores desses artigos, pensamos que uma instrumentalização teórica a respeito das relações interpessoais, embora necessária e importante, é insuficiente para catalisar transformações do cuidado em saúde e o desenvolvimento de ações mais solidárias. No nosso entendimento, por mais que as estratégias de capacitação profissional sejam importantes, elas não garantem, por si só, a qualidade do cuidado prestado à população. Compreendemos que os profissionais de saúde estão permeados por uma série de influências, tais como interesses e necessidades de diferentes níveis e qualidades, que tornam ainda mais difícil o desafio de transformação do modo como o cuidado é prestado nas organizações de saúde.

Os serviços de saúde são compostos por diversos atores com interesses, valores e projetos distintos, que disputam sentidos para o trabalho (Cecílio, 2007) e têm desejos e vontades que não necessariamente condizem com os ideais das experiências e propostas de humanização.

Além disso, a discussão sobre a efetivação de um cuidado mais solidário e produtor de autonomia deve considerar algumas características socioculturais que vão além daquelas que são inerentes às organizações de saúde. Conforme aponta Birman (2006, 2010), existem empecilhos próprios à dinâmica social que atravessam toda a vida contemporânea (inclusive os serviços de saúde), reforçando modos de subjetivação e sociabilidade pautados na autossuficiência e na negação e desqualificação do outro. Tais modos de subjetivação e sociabilidade têm impactos no cuidado em saúde, em especial quando compreendemos que na base do cuidado deve-se considerar a corresponsabilização por parte dos profissionais de saúde e dos gestores sobre o estado de saúde da população atendida.

Assim, entendemos que a responsabilização pelo cuidado se dá não somente através da responsabili- 
dade legal e normativa que os profissionais de saúde têm, mas atravessa as relações entre sujeitos inseridos numa dinâmica subjetiva e social caracterizada em nosso momento histórico pela exacerbação do individualismo e desinvestimento das instâncias coletivas para resolução de problemas sociais. Tais características, a nosso ver, dificultam a construção de um cuidado mais fraterno e produtor de autonomia.

4. Usuário como cliente e trabalhador, como alguém que deve desenvolver um espírito empreendedor/foco na qualidade do produto

Apesar da ocorrência, de maneira mais clara, em apenas um artigo (Backes e col., 2007), chama atenção a importação da lógica coorporativa para o setor saúde, trazendo consigo a concepção do usuário enquanto um cliente a ser atendido na complexidade de suas demandas. A argumentação do autor aponta para a necessidade de o profissional de saúde se imbuir de um espírito empreendedor e proativo (centrado em um caráter humanista) para atender as expectativas do mercado de saúde:

Os hospitais, assim como as demais instituições empresariais, necessitam estimular continuamente uma nova imagem organizacional centrada no ser humano enquanto estratégia para garantir a excelência e credibilidade nos serviços (Backes e col., 2007, p. 165).

A lógica da competitividade se encontra fortemente presente no discurso do autor e a humanização se apresenta enquanto um diferencial competitivo através do desenvolvimento de um caráter empreendedor nos profissionais de saúde, que organizados em equipes, realizariam um cuidado mais "humano".

O humano é entendido pelo autor enquanto um indivíduo cuja essência é caracterizada pela sua unicidade, indivisibilidade, autonomia e liberdade de escolha. Dessa forma, o cuidado que lhe é oferecido deve levar esses aspectos em consideração: Importa, sim, que o cuidado de enfermagem prime pela essência do ser humano enquanto um ser único, indivisível, autônomo e com liberdade de escolha, isto é, prime pela compreensão do ser humano enquanto um ser integral (Backes e col., 2007, p. 170, grifo nosso).
Parece haver o entendimento de autonomia enquanto a liberdade que o indivíduo (usuário) tem para escolher, dentro do cardápio de ações de saúde, aquela que seria mais adequada para o seu consumo.

Podemos tencionar essa concepção dialogando com as ideias de Onocko Campos e Campos (2006), que defendem que a autonomia é algo a ser "coconstruída" na relação entre profissional de saúde e o usuário, tendo como produto a criação de um novo modo de o usuário lidar com sua "rede de dependências".

Os autores entendem que a autonomia nunca se apresenta em totalidade, não havendo a existência, portanto, de uma liberdade total que nos possibilitasse abrir mão da relação com o outro e todo o sistema sociocultural em que estamos inseridos.

Diferente disso, parece-nos que a autonomia que Backes e colaboradores (2007) defendem vai ao encontro de uma lógica neoliberal que concebe as ações em saúde enquanto algo que deve ser regido pelo mercado - "a oferta deve se adaptar à demanda". Dessa forma, nos cabe questionar: que implicações esse modo de entender o sujeito traz para a gestão dos serviços públicos de saúde? Para além da discussão a respeito dos impactos que o modelo neoliberal tem sobre a eficiência desses serviços (temática trabalhada por diversos autores do campo da Saúde Coletiva), que outros impactos podem surgir sobre a produção do cuidado em saúde?

O individualismo e a competitividade produzidos pela lógica neoliberal se constituem como entrave para a realização de mudanças sociais, bem como de mudanças individuais (Enriquez, 2001). Isso se mostra ainda mais claro no contexto de empresas de grande porte, mas não é impossível que ocorra (ou que já esteja ocorrendo) uma importação desse modo de funcionamento para as organizações de saúde.

$\mathrm{O}$ individualismo presente em nossa sociedade tem por resultado, algumas vezes, colocar o trabalhador como o único responsável por suas competências e fracassos. Assim, caberia a este desenvolver suas capacidades técnicas, mas também psíquicas (como, por exemplo, desenvolver sua capacidade de autoconfiança para lidar com os obstáculos que surgem no decorrer do trabalho, ou tornar-se criativo para produzir inovações nas organizações) para se adequar às demandas que o mercado flexível impõe. 


\section{Considerações finais}

Na análise dos artigos, identificamos que a autonomia do trabalhador é pouco colocada em discussão. Os trabalhadores são entendidos como portadores de certo voluntarismo pessoal e, principalmente, como sujeitos que devem desenvolver capacidades que lhes possibilitariam transformar o modo como se dá o cuidado em saúde, tornando-o "humanizado".

O individualismo presente no modo como o profissional de saúde e o usuário são vistos em algumas dessas experiências parece reafirmar a ideia de que a qualificação do cuidado depende mais da "vontade de cada um" e, principalmente, da capacidade a ser desenvolvida pelos profissionais de saúde. Entretanto, tal capacidade é referida sem uma problematização acerca das condições subjetivas, organizacionais/político-institucionais e sociais que as subjazem; não havendo, por exemplo, uma discussão sobre o fortalecimento de redes e coletivos.

A humanização, pelo que se pôde perceber através da análise dos artigos, parece ser desejada principalmente em sua dimensão mais focada no atendimento. Porém, parece haver menores investimentos em propostas de democratização dos espaços de gestão, como a criação de conselhos e colegiados de gestão, inclusão dos diversos atores nos processos de gestão; construção de projetos terapêuticos; ampliação do horário de visitas; formação de equipes interdisciplinares de referência; dentre outras propostas presentes em documentos oficiais a respeito do tema e na produção teórica no campo do planejamento e gestão em saúde (Campos e Amaral, 2007; Brasil, 2010).

Dessa forma, acreditamos que os projetos de transformação no modo como se dá o cuidado em busca de solidariedade, cooperação e autonomia colocam à luz do dia a complexidade de realizar mudanças profundas nas organizações de saúde e a distância entre, por um lado, o que é proposto pelas políticas públicas em saúde e debatido no campo acadêmico enquanto novos modos de cuidar e gerir e, por outro, o que é desejado, e também o que é possível de ser realizado, por aqueles que executam essas políticas nos serviços de saúde.

\section{Referências}

AMESTOY, S. C.; SCHWARTZ, E.; THOFEHRN,

M. B. A humanização do trabalho para os profissionais de enfermagem. Acta Paulista de Enfermagem, São Paulo, v. 19, n. 4, p. 444-449, 2006.

AZEVEDO, C. S.; BRAGA NETO, F. C.; SÁ, M. C. Indivíduo e a mudança nas organizações de saúde: contribuições da psicossociologia. Cadernos de Saúde Pública, Rio de janeiro, v. 18, n. 1, p. 235-247, 2002.

BACKES, D. S. et al. O produto do serviço de enfermagem na perspectiva da gerência da qualidade. Revista Gaúcha de Enfermagem, Porto Alegre, v. 28, n. 2, p. 163-170, 2007.

BARBOSA, I. A.; SILVA, M. J. P. Cuidado humanizado de enfermagem: o agir com respeito em um hospital universitário. Revista Brasileira de Enfermagem, Brasília, DF, v. 6o, n. 5, p. 546-551, 2007.

BAZON, F. V. M.; CAMPANELLI, E. A.; BLASCOVIASSIS, S. M. A importância da humanização profissional no diagnóstico das deficiências. Psicologia - Teoria e Prática, São Paulo, v. 6, n. 2, p. 89-99, 2004.

BECCARIA, L. M. et al. Visita em Unidades de Terapia Intensiva: concepção dos familiares quanto à humanização do atendimento. Arquivo de Ciências da Saúde, São José do Rio Preto, v. 15, n. 2, p. $65-69,2008$.

BENEVIDES, R.; PASSOS, E. Humanização na saúde: um novo modismo? Interface Comunicação, Saúde, Educação, Botucatu, v. 9, n. 17, p. 389-394, 2005.

BIRMAN, J. Arquivos do mal-estar e da resistência. Rio de Janeiro: Civilização Brasileira, 2006.

BIRMAN, J. Governabilidade, força e sublimação: Freud e a filosofia política. Psicologia USP, São Paulo, v. 21, n. 3, p. 531-556, 2010.

BRASIL. Ministério da Saúde. HumanizaSUS: documento base para gestores e trabalhadores do SUS. 4. ed. Brasília, DF, 2010. 
CAMPOS, G. W. S. Cogestão e neoartesanato: elementos conceituais para repensar o trabalho em saúde combinando responsabilidade e autonomia. Ciência e Saúde Coletiva, Rio de Janeiro, v. 15, n. 5, p. 2337-2344, 2010.

CAMPOS, G. W. S.; AMARAL, M. A. A clínica ampliada e compartilhada, a gestão democrática e redes de atenção como referenciais teóricooperacionais para a reforma do hospital. Ciência e Saúde Coletiva, Rio de Janeiro, v. 12, n. 4, p. 849859, 2007.

CECÍLIO, L. C. O. O "trabalhador moral" na saúde: reflexões sobre um conceito. Interface Comunicação, Saúde, Educação, Botucatu, v. 11, n. 22, p. 345-351, 2007.

COELHO, L. P.; RODRIGUES, B. M. R. D. O cuidar da criança na perspectiva da bioética. Revista de Enfermagem da UERJ, Rio de Janeiro, v. 17, n. 2, p. 188-193, 2009.

COLLET, N.; ROCHA, S. M. M. Criança

hospitalizada: mãe e enfermagem compartilhando o cuidado. Revista Latino-Americana de

Enfermagem, Ribeirão Preto, v. 12, n. 2, p. 191-197, 2004 .

COSTA, J. F. O risco de cada um: e outros ensaios de psicanálise e cultura. Rio de Janeiro: Garamond, 2001.

COSTA, E.; BORENSTEIN, M. S. Problematizando para humanizar: uma proposta de transformação do cuidado em uma enfermaria psiquiátrica. Texto e Contexto - Enfermagem, Florianópolis, v. 13, n. 1, p. 163-170, 2004 .

DESLANDES, S. F. Análise do discurso oficial sobre a humanização da assistência hospitalar. Ciência e Saúde Coletiva, Rio de Janeiro, v. 9, n. 1, p. 7-14, 2004.

DIAS, M. A. B.; DOMINGUES, R. M. S. M. Desafios na implantação de uma política de humanização da assistência hospitalar ao parto. Ciência e Saúde Coletiva, Rio de Janeiro, v. 10, n. 3, p. 699-705, 2005 .
ENRIQUEZ, E. A interioridade está acabando? In: LÉVY, A. et al. (Org.). Psicossociologia: análise social e intervenção. Belo Horizonte: Autêntica, 2001. p. 45-61.

FERREIRA NETO, J. L. et al. Usos da noção de subjetividade no campo da saúde coletiva. Cadernos de Saúde Pública. Rio de Janeiro, v. 27, n. 5, p. 831-842, 2011.

GOMES, A. M. A. et al. Etno-avaliação da humanização hospitalar pelo usuário do Sistema Único de Saúde (SUS) e seus mediadores. Revista da Escola de Enfermagem da USP, São Paulo, v. 42, n. 4, p. 635-642, 2008.

ISEHARD, A. R. M. et. al. Práticas culturais de cuidados de mulheres mães de recém-nascidos de risco do sul do Brasil. Escola Anna Nery Revista de Enfermagem, Rio de Janeiro, v. 13, n. 1, p. 116122, 2009.

MARTINS, J. J. et al. A percepção da equipe de saúde e do idoso hospitalizado em relação ao cuidado humanizado. Arquivos Catarinenses de Medicina, Florianópolis, v. 37, n. 1, p. 30-37, 2008.

MENDES, I. et al. Diagnóstico e prognóstico graves: dificuldades para comunicar ao paciente e à família. Ciência, Cuidado e Saúde, Maringá, v. 6, n. 3, p. 300-304, 2008.

MERHY, E. E. A perda da dimensão cuidadora na produção da saúde: uma discussão do modelo assistencial e da intervenção no seu modo de trabalhar a assistência. In: CAMPOS, C. R. et al. Sistema Único de Saúde em Belo Horizonte: reescrevendo o público. São Paulo: Xamã, 1998. p. 103-120.

MOTTA, I. S. A relação interpessoal entre profissionais de saúde e a mulher em abortamento incompleto: "o olhar da mulher". Revista Brasileira de Saúde Materno Infantil, Recife, v. 5, n. 2, p. 219-228, 2005.

OLIVEIRA, B. R. G. et al. O processo de trabalho da equipe de enfermagem na UTI Neonatal e o cuidar humanizado. Texto e Contexto - Enfermagem, Florianópolis, v. 15, p. 105-113, 2006. Número especial. 
ONOCKO CAMPOS, R. T. O encontro trabalhadorusuário na atenção à saúde: uma contribuição da narrativa psicanalítica ao tema do sujeito na saúde coletiva. Ciência e Saúde Coletiva, Rio de Janeiro, v. 10, n. 3, p. 573-583, 2005.

ONOCKO CAMPOS, R. T.; CAMPOS, G. W. S. Coconstrução de autonomia: o sujeito em questão. In: CAMPOS, G. W. S. et al. (Org.). Tratado de saúde coletiva. São Paulo: Hucitec, 2006. v. 1, p. 669-714.

PROCHET, T. C.; SILVA, M. J. P. Situações de desconforto vivenciadas pelo idoso hospitalizado com a invasão do espaço pessoal e territorial. Escola Anna Nery Revista de Enfermagem, Rio de Janeiro, v. 12, n. 2, p. 310-315, 2008.

PUPLAKSIS, N. V.; RAMOS, D. L. P. Percepção dos alunos de Instituição de ensino superior de Odontologia de São Paulo e dos usuários dos atendimentos odontológicos sobre aspectos éticos. RPG Revista da Pós-Graduação da FOUSP, São Paulo, v. 13, n. 4, p. 318-323, 2006.
SÁ, M. C. A fraternidade em questão: um olhar psicossociológico sobre o cuidado e a "humanização" das práticas de saúde. Interface Comunicação, Saúde, Educação. Botucatu, v. 13, p. 651-664, 2009. Suplemento 1.

SANTOS, V. M. G. Humanização nos serviços: experiência voltada à educação permanente. Revista Baiana de Saúde Pública, Salvador, v. 31, p. 54-6o, 2007. Suplemento 1.

SEIBERT, S. L.; GOMES, M. L.; VARGENS, O. M. C. Assistência pré-natal da casa de parto do Rio de Janeiro: a visão de suas usuárias. Escola Anna Nery Revista de Enfermagem, Rio de Janeiro, v. 12, n. 4, p. 758-764, 2008.

SILVA, N. D.; CONTRIN, L. M. Orientações do enfermeiro dirigidas aos familiares dos pacientes internados na UTI no momento da visita. Arquivo de Ciências da Saúde, São José do Rio Preto, v. 14, n. 3, p. 148-152, 2007. 